\title{
A new Cyrtoneuropsis Malloch from Brazil (Diptera, Muscidae)
}

\author{
Márcia S. Couri ${ }^{1,2} \&$ Viviane Rodrigues de Sousa ${ }^{1,3}$
}

\author{
'Departamento de Entomologia, Museu Nacional, Quinta da Boa Vista, São Cristóvão s/n, 20940-040 Rio de Janeiro-RJ, Brasil. \\ courimarcia@gmail.com \\ ${ }^{2} \mathrm{CNPq}$ fellow \\ ${ }^{3} \mathrm{CNPq} / \mathrm{PIBIC} / \mathrm{UFRJ}$ scholarship
}

\begin{abstract}
A new Cyrtoneuropsis Malloch from Brazil (Diptera, Muscidae). This paper presents the description of a new species of Cyrtoneuropsis Malloch from São Carlos, São Paulo providing illustrations of the male and female terminalia and with a brief discussion on its systematic position within the genus.
\end{abstract}

KEYWORDS. Morphology; new species; taxonomy.

RESUMO. Um novo Cyrtoneuropsis Malloch do Brasil (Diptera, Muscidae). O trabalho apresenta a descrição de uma nova espécie de Cyrtoneuropsis Malloch de São Carlos, São Paulo, com ilustrações das terminálias masculina e feminina e uma breve discussão sobre sua posição sistemática dentro do gênero.

PALAVRAS-CHAVE. Morfologia; nova espécie; taxonomia

A phylogenetic study published by Pamplona (1999) on the former Cyrtoneurina Giglio-Tos resulted in the division of this genus into two monophyletic genera: Cyrtoneurina, with nine species and Paracyrtoneurina, a new genus erected in that paper to the other 31 species. Pamplona \& Pont (2000) synonymized Paracyrtoneurina with Cyrtoneuropsis Malloch.

Cyrtoneuropsis species can be recognized by the presence of cilia on ventral surface of wing vein $\mathrm{R}_{1}$; medium or short ovipositor with abdominal tergites 6-7 slender or large and with or without strong setae with round apex; cerci short, large and flat and hypoproct with a lateral incision. These are the main morphological differences, especially regarding the female terminalia to distinguish this genus from Cyrtoneurina.

Today, Cyrtoneuropsis includes 34 valid species, distributed throughout the Neotropical region (Carvalho et al. 2005). This paper aims to present a description of a new species of Cyrtoneuropsis.

\section{MATERIAL AND METHODS}

The material studied is deposited at Museu Nacional collection (Rio de Janeiro, Brazil, MNRJ). For the identification we used the taxonomic key of Couri \& Carvalho (2002) and comparisons with the material in the collection. The terminalia was clarified in $10 \%$ potassium hydroxide solution for 48 hours and then dissected in glycerin under stereomicroscope. The drawings were made with an optical microscope using a camera lucid. The terminology follows McAlpine (1981), except for "postpedicel", used for "antennal flagellomere", following Stuckenberg (1999).
To test the position of the new species in the classification proposed by Pamplona (1999) we used the same matrix with 45 characters and the same out-groups and the cladistic analysis was carried out using Hennig86 (Farris 1988). The cladograms were generated using "mhennig" and "branch swapping" associated with "successive weighting".

\section{Cyrtoneuropsis spinosa sp. nov.}

$$
\text { (Figs. 1-8) }
$$

Length. Male: body: $5 \mathrm{~mm}$ : wing: $5 \mathrm{~mm}$.

General coloration. Head with frons, face, parafacial and fronto-orbital plate silver; lunule orange brown; gena orange brown; antenna with apex of pedicel and base of postpedicel orange brown and arista light brown; proboscis and palpus dark brown: thorax dark brown, grey pollinose; two brown median vittae and two lateral ones thinner than the median. Anterior spiracle light yellow; posterior spiracle brown; halter light yellow; wing with brownish faint marks on apex of $\mathrm{R}_{1}$ and around the $\mathrm{r}-\mathrm{m}$ cross vein; legs brown with femurtibial joins yellow; pulvilli light yellow.

Head. Eyes fine and sparsely ciliated with internal margins diverging towards vertex, separated by a space about one third of head width at anterior ocellus level; nine pairs of fronto orbital setae, the basal and the apical ones stronger and the apical one strongly curved forward; antenna inserted below middle of eyes; antenna with postpedicel 2.2 as long as pedicel; arista plumose with about 14 cilia, secondary dorsal cilia present; vibrissa strong, longer than the length of arista; palpus barrel-shaped, with long cilia at base and apex.

Thorax. Acrostichals 0:1; dorsocentrals 2:4; two postpronotals, the anterior more developed than the posterior; 

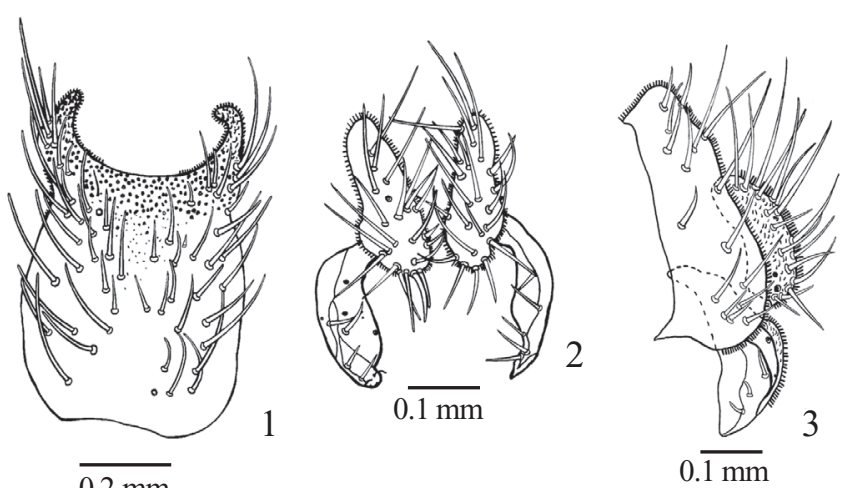

$\overline{0.2 \mathrm{~mm}}$

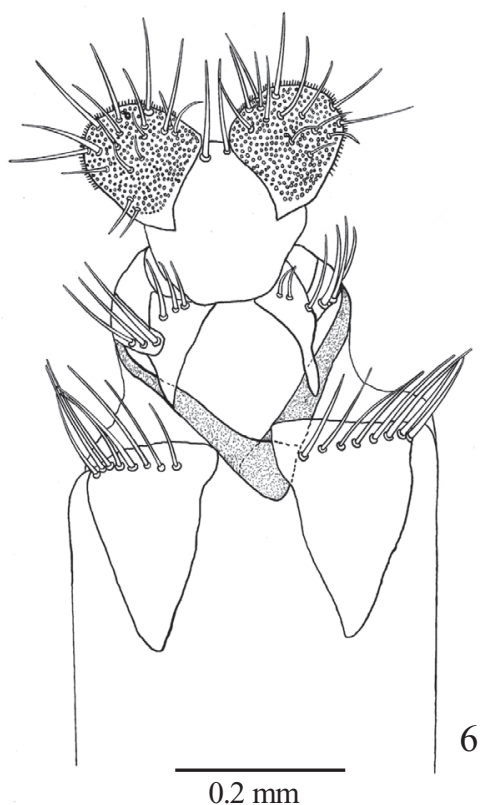

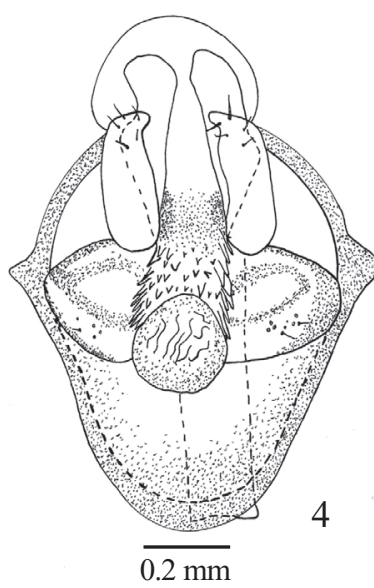
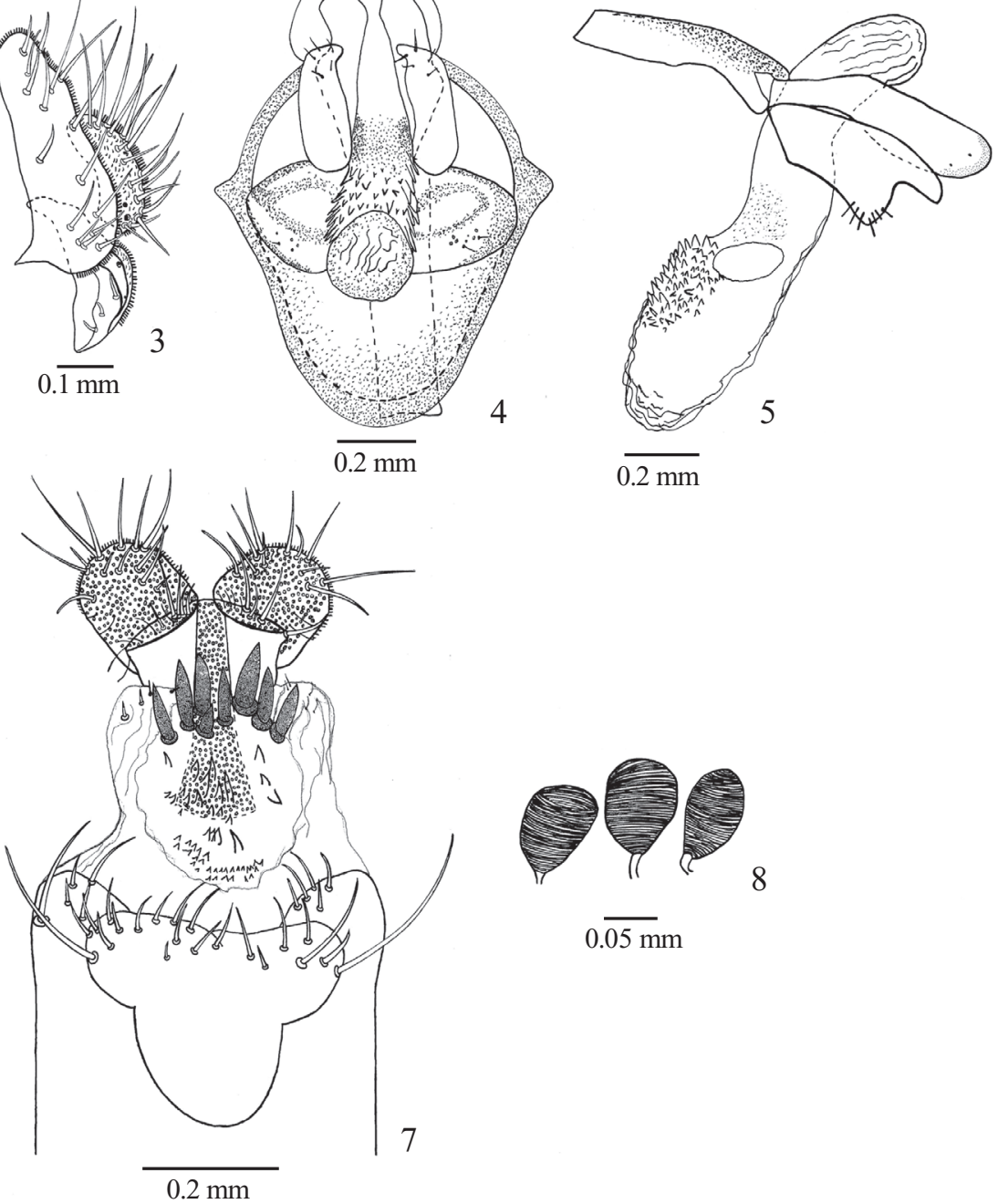

$0 . \overline{05 \mathrm{~mm}}$

Figs. 1-8. Cyrtoneuropsis spinosa sp. nov.: 1, male, sternite 5; 2, cercal plate, dorsal view; 3, cercal plate, lateral view; 4, aedeagus, dorsal view; 5, aedeagus, lateral view; 6 , ovipositor, dorsal view; 7 , ovipositor, ventral view; 8 , spermatheca.

two presuturals; 3 intralars; one pre-alar; two supra-alars; notopleuron with two setae; scutellum with one pair of basal setae, three pairs of lateral setae and one apical pair; prosternum bare; two proepisternals; propleuron bare; anterior spiracle vertical and elongated; anepisternum with cilia and a series of seven setae on the posterior edge; katepisternals 1:2 with the posterior superior seta longer than the others; anepimeron with cilia; katepimeron bare; posterior spiracle horizontal and elongate; lower calypter measuring about 1.6 to 1.7 the upper one. Wing with $\mathrm{R}_{1}$ with cilia on ventral surface only at the apex; node of $R_{4+5}$ with cilia on both surfaces. Legs with fore femur on anterodorsal, anteroventral and dorsal surfaces with a complete row of strong setae. Fore tibia on dorsal and anterodorsal surfaces with a preapical seta and anteroventral surface with one apical seta. Mid femur on ventral surface with a row of setae more developed in basal half; posterior surface with two preapical setae. Mid tibia on anteroventral surface with two setae; dorsal and ventral surfaces with an apical seta, the last one longer. Hind femur with a row of setae on anterodorsal and posterodorsal surfaces. Hind tibia with a dorsal and an anterodorsal preapical seta and an anteroventral apical one.

Abdomen. Sternite 1 with lateral cilia. Sternite 5 (Fig. 1) with central reentrance on the posterior margin rounded; dorsal microtrichia on apical fourths; long setae along almost its entire surface.

Terminalia. Cercal plate higher than wide, with long setae and short cilia on the edge; surstylus long and thin with long spines on inner margin (Figs. 2-3); gonopode rounded at the base, with lateral hairs and small spines at the apex; aedeagus with basiphallus membranous, distiphallus with spines, larger on sides than in center; apodeme of aedeagus not exceeding the margin of hypandrium (Figs. 4-5).

Female. Similar to male, differing as follows: interocular space about 0.45 to 0.47 of head width at level of anterior ocellus; arista with 22 cilia.

Ovipositor. Short, epiproct rounded, with two setae at apex, hipoproct with a projection with microtrichia, reach- 
ing half of segment 8; cercus round, with microtrichia in all its extension; ventral surface with the membrane of segment 8 with small spines and the apex with a row of large spines (Figs 6 and 7). Spermatheca as in Fig. 8.

Type material (MNRJ): Holotype male: BRAZIL: São Paulo, São Carlos, Fazenda Canchim (?), 11.iii.1993, Helio Mendes col. Paratypes: same data as holotype; 1 male and 3 females; 29.x.1992, 1 male and 1 female.

Etymology. The name refers to the very strong spines in female ovipositor.

Discussion. Cyrtoneuropsis spinosa sp. nov. is morphologically similar to C. pararescita (Couri, 1995) and C. rescita (Walker, 1861), differing from both by the colour of pedicel and legs, but mainly by the morphology of female and male terminalia. As stated in Couri (1995) and referred before by Snyder (1954), in this genus we can find species with very similar terminalia and striking differences on chaetotaxy and also species very similar morphologically with distinctive differences in the terminalia. Inserting the new species in Pamplona's (1999) cladistic analysis, it appears apical in the cladogram, in the base of the clade formed by $C$. ocasionalis Couri, C. pararescita $+C$. rescita.

\section{ACKNOWLEDGMENTS}

The authors are grateful to Dr. Andre Mallemont Cunha (Museu de Zoologia de São Paulo) for the help in the final manuscript. MSC is grateful to Conselho Nacional de Desen- volvimento Científico e Tecnológico (CNPq, processes 3013012007-7) for the financial support and VRS for the CNPq/PIBIC/UFRJ scholarship.

\section{REFERENCES}

Carvalho, C. J. B. de; M. S. Couri; A. C. Pont, A.; D. Pamplona \& S. M. Lopes. 2005. A catalogue of the Muscidae (Diptera) of the Neotropical Region. Zootaxa 860: 1-282.

Couri, M. S. \& C. J. B. de Carvalho. 2002. Part II Apical groups, p. $133-$ 257. In: C. J. B. de Carvalho (ed.). Muscidae (Diptera) of the Neotropical Region: Taxonomy. Editora Universidade Federal do Paraná, $287 \mathrm{p}$

Couri, M. S. 1995. Uma nova espécie de Cyrtoneurina Giglio-Tos do Brasil (Diptera, Muscidae). Revista Brasileira de Zoologia 12: 229-232

Farris, J.S. 1988. Hennig 1986. Version 1.5. Published by the author, New York.

McAlpine, J. F. 1981. Morphology and terminology - adults, p. 9-63. In: J. F. McAlpine; B. V. Peterson; G. E. Shewell; H. J. Teskey; J. R. Vockeroth \& D. M. Wood (eds.). Manual of Nearctic Diptera, volume 1. Research Branch, Agriculture Canada, Monograph, 27, vol. 1, 674 p.

Pamplona, D. 1999. Nova caracterização de Cyrtoneurina Giglio-Tos, 1893 e descrição de Paracyrtoneurina gen. nov. (Diptera, Muscidae). Revista Brasileira de Entomologia 43: 9-24.

Pamplona, D. \& A. C. Pont. 2000. A note on the genus Paracyrtoneurina Pamplona, 1999 (Diptera, Muscidae). Studia dipterologica 7: 223-224.

Snyder, F. M. 1954. A Revision of Cyrtoneurina Giglio-Tos, with notes on related genera (Diptera, Muscidae). Bulletin of the American Museum of Natural History 103: 417-464.

Stuckenberg, B. R. 1999. Antennal evolution in the Brachycera (Diptera), with a reassessment of terminology relating to the flagellum. Studia dipterologica 6: $33-48$. 